\title{
ALGUNOS ELEMENTOS SOBRE EL INTENTO DE INSTITUCIONALIZAR UNA TRADICIÓN SOCIOLÓGICA CIENTÍFICA Y REFORMISTA EN ESPAÑA (1931-1936)
}

\author{
Juan Jesús Morales Martín \\ INCIHUSA-CONICET CCT-Mendoza \\ jmorales@mendoza-conicet.gob.ar
}

http://dx.doi.org/10.5209/rev_NOMA.2014.v43.n3.49282

\begin{abstract}
Resumen: El propósito de este artículo es examinar e interpretar el estado de la sociología en la España anterior a la Guerra Civil. La hipótesis que guía este trabajo es que antes del levantamiento militar de julio de 1936 esta ciencia social estaba en condiciones para asumir un grado de especialización necesario para su enseñanza, para la investigación empírica y para encabezar prácticas reformistas. Pues la sociología, aún siendo una disciplina relativamente joven, se unió al proyecto de modernización social y político que asumió la ciencia española durante el primer tercio del siglo XX. Observaremos, en consecuencia, el papel destacado de algunos nombres, como los de Adolfo Posada, Francisco Ayala o José Medina Echavarría, quienes trataron de consolidar una tradición sociológica científica y reformista.
\end{abstract}

Palabras clave: Adolfo Posada, Francisco Ayala, José Medina Echavarría, sociología española, tradición sociológica, herencias culturales.

Abstract: In this article, we will examine and interpret the state of sociology before the Spanish Civil War. The hypothesis of this work is that before the military uprising of July 1936 this social science was able to assume a degree of specialization necessary for teaching, for empirical research and to lead reform practices. Mainly because sociology, despite being a relatively young discipline, joined the project of social and political modernization that took Spanish science during the first third of the twentieth century. Observe, therefore, the prominent role of some names, such as Adolfo Posada, Francisco Ayala and José Medina Echavarría, who tried to build a scientific and sociological reformist tradition.

Keywords: Adolfo Posada, Francisco Ayala, José Medina Echavarría, sociology in Spain, sociological tradition, cultural heritages.

\section{Desconocimientos y olvidos en la sociología española. A modo de introducción.}

Los sociólogos en España nos hemos acostumbrado a ver la historia de nuestra disciplina de una manera superficial y periférica, con ausencia clara de profundizar (Sarabia, 2001:17). Somos una comunidad intelectual que no lee a sus clásicos. Como acertadamente ha indicado Alberto Ribes (2011:553), la sociología española es una ciencia que está en constante "alumbramiento". La norma habitual de sus practicantes ha sido la de creer que la sociología sólo comenzaba con ellos mismos. No nos hemos tomado en serio el pasado de nuestra disciplina, como asegura Salvador Giner (2007: XLII). A los sociólogos nos queda el consuelo de que la falta de interés por la historia de la disciplina no sólo es manía de nuestro campo, sino de toda la ciencia española (LópezOcón, 2003:13). No nos debe sorprender, por tanto, la reducción historiográfica en la narración de la sociología porque es un mal congénito de toda nuestra ciencia. 
Todavía falta una reflexión crítica sistematizada sobre la propia sociología española, a pesar de que en los últimos años se vienen realizando diversas visiones panorámicas sobre el proceso histórico en el que se ha configurado el campo sociológico (Giner, 1990; Del Campo, 2001). Por eso aquí asumimos una "narrativa abierta" sobre la historia de la sociología en España que pretende analizar, conocer y comprender "las formas sociológicas del pasado" desde la dimensión epistemológica y teórica que nos concede el presente (Ribes, 2011:555). En esta investigación he pretendido revisar algunas posiciones afianzadas que no habían sido tenidas en cuenta en estudios sobre la historia de la sociología española como, por ejemplo, los marcos institucionales y sociales gracias a los cuales se fue hilvanando y forjando un pensamiento sociológico. Lo que me he propuesto es comprobar cómo en España había sociología antes de la Guerra Civil y, sobre todo, cómo hubo un pensamiento colectivo que trató de constituir un discurso sociológico en clave propia.

De esta manera, el objetivo principal de este trabajo de investigación es documentar e interpretar los términos de la contribución de Adolfo Posada, Francisco Ayala y José Medina Echavarría para que la sociología se constituyera en España como una disciplina autónoma y científica. Estos autores fueron actores, gestores y partícipes del movimiento sociológico que se dio en nuestro país durante la década del 30 del pasado siglo. Portaron y representaron distintas tradiciones sociológicas, sobre todo la anglosajona y la alemana, que trataron de introducirlas desde diferentes instituciones, medios y latitudes. Tuvieron un interés consciente por gestar un programa de investigación sociológica $y$, sobre todo, quisieron desarrollar epistemológicamente en lengua castellana a la "nueva ciencia". Las actividades editoriales, los libros y las traducciones vehicularon una visión compartida de la sociología. Pero además este intercambio también tuvo otros intereses: incorporaron a su preocupación sociológica un matiz reformista y una perspectiva democrática ligados a los sucesos históricos del momento.

La combinación de un enfoque teórico que armoniza biografía, historia, redes intelectuales y sociología es el que nos va a permitir pensar y reflexionar sobre una de las experiencias más desconocidas, pero fructíferas de la historia del pensamiento social español. Se trata de tejer, como sugerían Bottomore y Nisbet (1979: VII) para estudios de este tipo, un relato alrededor de cómo el análisis y la perspectiva sociológica crecen en conexión a la realidad social concreta. Por tal motivo, esta investigación narra el surgimiento de una tradición sociológica científica y reformista muy influida por el marco de la Segunda República y que, por consecuencia, de la posterior Guerra Civil se perdió. Hay un antes y un después de ese hecho histórico que hace muy difícil trazar continuidades. Esta fractura ha repercutido en el avance posterior de la sociología en España al desatender a sus clásicos, a las herencias y a las tradiciones sociológicas anteriores. Aquella discontinuidad y la posterior institucionalización de la sociología bajo el horizonte cultural del franquismo distorsionaron el conocimiento de la obra de autores como Ayala, Medina Echavarría o Posada. 
La utilidad de la recuperación crítica del legado de la sociología en lengua castellana es evidente en las páginas que siguen. Creo que en el contexto actual marcado por la colonización académica e intelectual, la puesta en valor y el análisis serio y riguroso de "nuestros" clásicos merece un espacio en los debates académicos. Ese fue también el mismo empeño de estos autores por pensar lo social. Estimo que este ejercicio crítico nos ayudará a la hora de reflexionar sobre los hallazgos que los pioneros y clásicos de la sociología española lograron, a la vez que constituye un testimonio de la actualidad de los mismos.

\section{Panorama de la sociología española de principios del siglo XX.}

El contexto socio-histórico de la sociología española de principios del siglo XX estuvo configurado por la primera crisis de la modernidad. Fue un momento en que la cultura europea se preguntó por primera vez en su historia sobre la crisis como una noción universal. Ese siglo se inició con un encadenamiento de hechos tan significativos como la revolución bolchevique, la Primera Guerra Mundial, la crisis de Weimar y el ascenso de Hitler al poder, la emergencia de los totalitarismos, la Tercera República francesa, la Segunda República española y, para culminar toda esta tempestad tan convulsa, la Guerra Civil española y la posterior Segunda Guerra Mundial. Fue una época, sin duda, de grandes y acelerados cambios que, sumados al desarrollo económico e industrial de Europa, trastocaron la fisonomía social y política de sus respectivas sociedades. Y España no fue ajena a estas modificaciones, ya que padeció en primera persona este tiempo de tierras movedizas, primero con la huelga de 1917, seguida de la dictadura de Primo de Rivera en 1923, la cual puso fin a las ilusiones reformistas iniciadas con el regeneracionismo y, por último, la Guerra Civil española que echó por tierra trágicamente todas las ilusiones modernizadoras puestas en la Segunda República.

No se puede decir que la sociología española de principios de siglo se hubiera constituido como un campo autónomo de conocimiento científico. Pero sí, en cambio, encontramos los primeros pasos hacia la modernización de la disciplina, aunque fueran de una forma aproximativa y tentativa. La poca sociología de esa época estuvo personificada, fundamentalmente, por cultivadores como Severino Aznar, José Ortega y Gasset y Adolfo Posada. Representó Aznar la corriente del catolicismo social, Ortega el ensayismo social de orientación historicista y mundana, y Posada la corriente liberalreformista (Rodríguez lbáñez, 2004: 199). Estas tres corrientes se desarrollaron desde diferentes ámbitos. Aznar ocupó en 1916 la cátedra de Sociología de la Universidad de Madrid tras la muerte de Manuel Sales y Ferré. Se preocupó por desarrollar una sociología institucional que tendría su máxima expresión tras la Guerra Civil, posicionándose cercana al régimen franquista y convirtiéndose en soporte de sus políticas sociales. A Severino Aznar, aún siendo Director del Instituto Balmes de Sociología entre 1943 y 1959 (nacido al albor del recién creado Consejo Superior de Investigaciones Científicas), no se le puede considerar exactamente como un sociólogo en el sentido estricto, ni ejerció como tal. Más que sociólogo, fue un demógrafo y un reformista 
interesado por la renovación social, hecho que le distancia de la sociología. Se le puede señalar, por tanto, como un continuador de de los movimientos de reforma social de raíces cristianas y como un destacado miembro del sector social del franquismo.

Por su parte, Ortega y Gasset desempeñó de 1910 a 1936 la cátedra de Metafísica de la Universidad de Madrid. Participó en la política nacional desde posturas abiertas y liberales, y se convirtió en espectador de su tiempo desde el cobijo de la Revista de Occidente. Mantuvo una proximidad con las corrientes intelectuales europeas, fundamentalmente con la filosofía alemana. Su motivación estuvo en situar al pensamiento español a la altura de le época. Una primera recepción de la sociología alemana se produjo a través de la editorial de la Revista de Occidente. Se publicaron entre 1924 y 1936 varias traducciones de las obras de George Simmel, destacando su Sociología. Estudio sobre las formas de socialización, de 1927. Se elaboraba una sociología de raíz neokantiana, rozando los márgenes de la filosofía social. Ortega, más que hacer sociología, realizó una filosofía social con mirada sociológica expuesta en obras como El tema de nuestro tiempo, de 1923, La rebelión de las masas, de 1930, Ideas y creencias, de 1940, y El hombre y la gente, su obra póstuma de 1957.

De los tres autores que hemos destacado, fue Posada el más preocupado por los estudios sociológicos. Colaboró en el Instituto de Reformas Sociales, del cual sería director entre 1920 y 1924, y ocupó la cátedra de Derecho Político de la Universidad de Madrid. Se dedicó tanto al estudio del derecho como a la sociología, intercalando en su obra estas dos preocupaciones. Estuvo influido por el pensamiento krausista español y por el positivismo comtiano, una conjunción de ambas corrientes filosóficas que él mismo denominó como "krauso-positivismo" (Posada, 1892). Su esfuerzo en el terreno sociológico estuvo en desligar a la sociología de la filosofía. Se interesó por los trabajos de Durkheim, compartiendo con el francés los principios de sistematización y esquematización de la construcción científica de la sociología. Además le interesó mucho la sociología norteamericana y especialmente la obra de figuras como Giddings, Small o Ward. También le influyeron sociólogos alemanes como Schäffle (discípulo de Krause), Ratzenhofer y Gumplowicz.

Este manejo de escuelas y direcciones que tomó la sociología de su época, confirma a Posada como el "gran renovador del panorama científico de las ciencias sociales españolas" (Gutiérrez, 2001: 92-93). Esto se aprecia en su producción académica. Sus trabajos iniciales referentes al derecho como Estudios sobre el régimen parlamentario en España, de 1891, o Teorías modernas sobre los orígenes de la familia, de la sociedad y del Estado, de 1892; se ven seguidos de obras que ya asumen el enfoque sociológico como pueden ser Los estudios sociológicos en España, de 1899, Literatura y problemas de sociología, de 1901 o Sobre las tendencias actuales de la sociología, de 1902. Además sacó a la luz en 1904 su libro Socialismo y reforma social, donde manifiesta el carácter reformista y práctico que otorgaba a la sociología. Su obra más importante es Principios de Sociología, de 1908. Un texto ciertamente relevante al plantear cuestiones como los orígenes de la sociología, su desenvolvimiento, la objetividad de esta ciencia social, la 
complejidad de su constitución científica, su relación con otras ciencias sociales o la correspondencia individuo-sociedad.

Estos Principios de Sociología tendrían una segunda edición revisada en 1929 y Posada ya no solamente examina las tendencias sociológicas desde Comte, pasando por autores como Durkheim, Sombart, Tarde, Vierkandt o Von Wiese, hasta llegar a Ward, como en la primera edición, sino que se aproxima a todas las corrientes contemporáneas hasta esa fecha. Además en esas páginas se adivina su interés por señalar la complicada formación de la sociología como pensamiento científico, reconociéndola como una disciplina aún en su formación inicial. Por ello no duda en sumarse a "la corriente central del pensamiento sociológico moderno", representada por estos autores y que para él significaba asumir la actitud científica tanto para definir a la sociología como para poder comprender y explicar la realidad social. En palabras del autor:

"La Sociología vivía fuera de la acción de la Metafísica, y aun de la Filosofía, estimándose necesario edificarla sobre meras bases de hecho, al modo de una ciencia experimental o de una disciplina meramente histórica; por otra parte, para justificar la existencia de la Sociología científica, se ha creído indispensable demostrar que hay algo característico, singular e irreducible en los fenómenos sociales" (Posada, 1929a: 3).

Posada no fue un autor solitario, sino que actuó en un espacio más amplio: la sociología europea y la sociología norteamericana. Fue un agente activo del circuito internacional de las ideas sociológicas de comienzos del siglo XX. Participó en congresos internacionales organizados por el Institut International de Sociologie, de París, creado en 1893 por intelectuales preocupados en el estudio de los problemas sociales y en el que destacaba, entre otros, René Worms. Allí conoció a otros sociólogos extranjeros que también estaban pensando sobre la función y el sentido de esta ciencia social. Cabe destacar su encuentro y afinidad con las ideas de Lester F. Ward (Posada, 1929b: 237). Además Posada siempre estuvo al día de las publicaciones sociológicas internacionales, destacando entre sus preferencias L'Année Sociologique, fundado por Émile Durkheim, la Revue Internationale de Sociologie o The American Journal of Sociology, de la Universidad de Chicago.

La figura de Posada fue importantísima a la hora de encabezar el proceso científico de la sociología en España. Su movilidad académica internacional ayuda a observar los mecanismos de apropiación del conocimiento generado en el extranjero y los contextos de enunciación de las teorías sociales. Su natural inclinación a mirar la sociedad desde una perspectiva científica la extrapoló a los ámbitos universitarios y fue acogida por alumnos suyos como Francisco Ayala y José Medina Echavarría, quienes habían viajado a Madrid para terminar su doctorado de Derecho a finales de los años 20. La mediación de Posada resultó significativa para estos estudiantes a la hora de influirles en su destino académico y en su acercamiento a los estudios sociológicos. A partir de ese encuentro en las aulas de la Universidad de Madrid estos autores compartieron un desafío: consolidar y madurar un "fondo común de pensamiento, que constituirá en definitiva el contenido propio, aunque variable, de la ciencia sociológica" (Posada, 1929a: 102). Un propósito acorde, sin duda, con el proceso de internacionalización de los estudios sociológicos. 


\section{Círculos de afinidad y condiciones institucionales para el conocimiento sociológico: la formación de una tradición sociológica.}

Ayala y Medina llegaron a Madrid, como dijimos, para hacer su doctorado con la intención de profundizar en la tradición del derecho español. Pero su propósito no era seguir investigando sobre España. Persuadidos por el clima de su tiempo, ambos viajan a Alemania en 1930; Ayala a Berlín y Medina a Marburgo. Fue una experiencia transcendental para sus trayectorias académicas, marcándoles intelectualmente para toda su vida. En Alemania encontraron una fuente de estímulos intelectuales al descubrir un nuevo mundo enriquecedor que explorar: universidades, librerías, profesores, seminarios, cursos, etc. Dispusieron de libros, ideas y de un clima anterior al acenso nacionalsocialista favorable para la ciencia (Lepenies, 1994). Allí completaron su formación, Ayala junto a Hermann Heller, y Medina junto a Eric Auerbach, Gerarhd Krüger y Karl Löwith. Los dos estudiantes españoles se interesaron por la punta del pensamiento alemán contemporáneo, representado por figuras como las de Heidegger, Husserl, Freyer, Tönnies, Simmel, Oppenheimer o los hermanos Weber. Estudiaron y se empaparon de la sociología comprensiva, del historicismo o de la fenomenología, corrientes que irán incorporando progresivamente en sus inquietudes intelectuales.

A la vuelta de estos viajes, los dos observan el entusiasmo aún reciente con el que se había proclamado la Segunda República el 14 de abril de 1931. Ayala y Medina se incorporan a la vez en el cuerpo de letrados del Congreso de los Diputados. Desde allí los dos amigos fueron espectadores privilegiados de la política española y del laboratorio de la Segunda República (Ayala, 2006: 184). Fueron unos años marcados por un espíritu renovador y modernizador que se propuso elevar el nivel económico y cultural del país. Pero también fue un tiempo convulso, ajetreado y ciertamente contradictorio. Les tocó vivir un momento histórico en el que se concentró un gran estallido de energía motivado por causas idealistas que compartieron millones de españoles. Había llegado la hora de que España escuchase "un llamamiento a la libertad" (Juliá, 1990: 39). Se abrió un horizonte cultural caracterizado por la vía democrática, por el parlamentarismo pacifista y social (también laico), la soberanía popular y la confianza en un Estado de Derecho.

La Segunda República simbolizó "la toma de poder" de la llamada "Generación del 14" o "Generación de los intelectuales", caracterizada por unas nuevas orientaciones ideológicas, estéticas y reformistas, que ya no eran las del modernismo ni las de la "Generación del 98" (Marichal, 1995: 242). El núcleo de esta generación estuvo representado por personalidades como las de Manuel Azaña, Eugenio D’Ors, Gregorio Marañón, José Ortega y Gasset, Salvador de Madariaga o Américo Castro. Esta "Generación del 14" identificó el problema español en el sentido que le había otorgado Ortega: esto es, como un "problema pedagógico" (López-Ocón, 2010: 48). Fue también el filósofo madrileño quien invitó a los intelectuales españoles a asumir la emoción liberal y el liberalismo. Por tal motivo, no extraña que Ayala y Medina se tomasen muy en serio esos tiempos, concienciados de que los problemas de España pasaban por una renovación cultural y educativa acorde a unos principios 
democráticos. Y la apuesta más personal de estos autores fue la de contribuir a esa historia colectiva desde el lado de la ciencia.

En esos años publican algunas de sus últimas y más relevantes obras jurídicas. Ayala escribe una serie de textos, como Problemas jurídico-sociales del jornal mínimo, de 1931, o El derecho social en la constitución de la República española, de 1932 (Ribes, 2007: 76). Medina publicaría en 1935, fruto de sus investigaciones en Alemania, La situación presente de la filosofía jurídica. Estos trabajos supusieron una contribución importante en la renovación de la doctrina jurídica republicana (Martín, 2011: CLXIV). Sin embargo, la perspectiva sociológica para enfrentar el estudio de lo social ya estaba presente en aquellas páginas. Hay una evidente prueba de este giro intelectual, por ejemplo, en el citado trabajo de Medina, donde se preguntaba sobre los requisitos metodológicos de la construcción científica de la sociología: "La Sociología se encontraba en el momento en que se renunciaba ya a la construcción de sistema enciclopédicos y empezaba a buscarse afanosamente el modo de llegar a una delimitación de su objeto propio, que la constituyese en una ciencia independiente y definida" (Medina, 1935: 91).

Muchas de estas reflexiones transitaban y bordeaban lugares comunes de lo "social". Sus expectativas intelectuales no supusieron su confinamiento en el derecho o la filosofía del derecho. Por el contrario, Ayala y Medina eran conscientes de que las circunstancias de su tiempo histórico empezaban a pasar por la sociología. Sin embargo, el pensamiento sociológico tenía unos apoyos académicos aún débiles. Uno de los dispositivos claves para la generación de una tradición sociológica es, sin duda, el soporte institucional. Ayala y Medina, junto al maestro Posada, fueron conscientes de que la enseñanza y la investigación de la sociología necesitaban de un reconocimiento tanto en los planes de estudios universitarios como en la instauración de centros de investigación. El primer ámbito sobre el que había que actuar era el educativo.

No había profesores de sociología a tiempo completo y de forma sistemática. La enseñanza de esta disciplina en España era impartida a través de cursos aislados pertenecientes al currículo de otras carreras. En las Universidades no existía la carrera de sociología como tal. Ante este hecho, Ayala, Medina y Posada tuvieron claro que la introducción de la sociología en los planes de estudios universitarios pasaba por su enseñanza, aunque fueran en cursos de doctorados de derecho. Entonces aprovechaban sus puestos docentes en la Universidad Central de Madrid para comenzar a difundir y a articular un discurso sociológico compartido. Cabe destacar que Ayala y Medina desarrollaron una carrera académica bastante pareja en esta universidad madrileña, Ayala como profesor auxiliar de Derecho y Medina como ayudante de clases de prácticas en la cátedra de Filosofía del Derecho de Adolfo Posada. ${ }^{1}$ Incluso impartió un curso completo de Sociología en aquella cátedra que tituló Introducción a la sociología contemporánea. Allí, por ejemplo, este autor afirmaba que "la enorme expansión que la Sociología ha tenido en estos últimos años no puede explicarse como un simple fenómeno de moda; sino porque responde a las exigencias espirituales más profundas del momento

\footnotetext{
${ }^{1}$ Archivo General de la Universidad Complutense de Madrid. Expediente de José Medina Echavarría.
} 
presente, ya que la Sociología es, en su sentido más íntimo, la expresión de una época crítica" (Medina, 1934: 4). Además Medina apuntaba lo siguiente sobre Max Weber y sobre la sociología:

\begin{abstract}
"Max Weber es una de las figuras más poderosas de la Sociología alemana. Proviniendo del campo de la economía y consagrado a investigaciones históricas, realiza en su obra inacabada "Economía y Sociedad", uno de los mayores esfuerzos por lograr un sistema de conceptos sociológicos. Recoge de Rickert la teoría de las ciencias y de Dilthey algunos de los conceptos fundamentales de este filósofo. Su obra ha podido llamarse una Sociología de la comprensión, porque la base metódica de ella es la teoría de la comprensión, desarrollada, sin embargo, con arreglo a una interpretación original" (Medina, 1934: 64).
\end{abstract}

La figura de Adolfo Posada fue clave a la hora de facilitarles a Ayala y a Medina espacios institucionales favorables para difundir los estudios sociológicos. Sabemos que los apoyó en diversos momentos de sus trayectorias académicas. Les firmó favorablemente varios documentos para distintas oposiciones de cátedra. ${ }^{2}$ En 1935 los dos jóvenes consiguen sendas cátedras de Filosofía del Derecho: Ayala en La Laguna y Medina en Murcia, ninguno de los dos llegará a ocuparlas. Su lugar estaba en Madrid, en sus trabajos en las Cortes republicanas, pero también estaban ocupados en promocionar la sociología. A raíz de las necesidades del Estado interventor, se generó un nuevo contexto para la actividad profesional del científico social. La sociología empezó a ser reconocida entonces por estos autores como la ciencia de la modernización. Y no sólo quisieron contribuir en el plano universitario con su enseñanza, sino que además apostaron decididamente, en un plano más amplio, por su divulgación editorial.

\title{
4. La sección de Sociología de la editorial de la Revista de Derecho Privado.
}

Ayala, Medina y Posada sintieron la necesidad de acompañar las exposiciones doctrinales de la disciplina sociológica con sus correspondientes manuales y fuentes bibliográficas para atraer a los futuros alumnos. Por tal motivo, concedieron mucha importancia a la formación del discurso sociológico desde diversas plataformas como revistas, editoriales, traducciones y publicaciones. Sabemos que entre 1933 y 1936 Medina fue encargado de la colección de Sociología de la editorial de la Revista de Derecho Privado, dirigida por Posada. Esta editorial contaba con otras colecciones dedicadas al derecho en las que habían realizado sus primeras traducciones un buen número de jóvenes académicos. Por ejemplo, Medina había traducido en 1933 el libro de Gustav Radbruch, Filosofía del derecho; Luis Recasens Siches, por aquel entonces catedrático en la Universidad Central de Madrid, tradujo Introducción a la ciencia del derecho, también de Gustav Radbruch; ${ }^{3}$ Eugenio Ímaz se

\footnotetext{
${ }^{2}$ Ayala es citado en las memorias de Posada (1983: 347) como uno de sus discípulos predilectos. Posada fue miembro del tribunal de tesis de José Medina, cuyo trabajo La representación profesional en las asambleas legislativas fue leído en mayo de 1930. Además existen varios documentos en los que Posada firma, como decano de la Facultad de Derecho de la Universidad Central, a favor de Medina para distintas oposiciones a cátedra en la Universidades de Granada y de Madrid entre 1934 y 1935. Archivo General de la Universidad Complutense de Madrid. Expediente de José Medina Echavarría.

${ }^{3}$ Luis Recasens Siches, al igual que Ayala y Medina Echavarría, compartió el interés por la sociología alemana. Precisamente se había formado en aquel país al disfrutar de una pensión de la Junta para
} 
ocupó de traducir la Teoría general del derecho administrativo, de Adolf Merkel; Vicente Herrero La crisis de la democracia, de Harold Laski; Francisco Ayala tradujo en 1934 la Teoría de la constitución, de Carl Schmitt y en 1936 La opinión pública, de Ernst Manheim; o Wenceslao Roces se encargó de la traducción del libro de Rudolph Sohm, Instituciones de derecho privado romano. Historia y sistema.

Observamos cómo en los anteriores títulos había todavía un interés por las corrientes jurídicas europeas. Sin embargo, la idea que subyace para que Posada encargase a Medina la dirección de la colección de Sociología fue la de ir constituyendo una base para la institucionalización de esta ciencia social. Habían comprendido que para institucionalizar la disciplina sociológica había que actuar en distintos frentes: "la producción literaria de quienes se dedican de modo especial al cultivo de la Sociología"; "la fundación de publicaciones que, por el arraigo que alcanzan, por su persistencia y continuidad, demuestran la existencia de un interés constante y sostenido, y más o menos general, por los problemas de la Sociología; nos referimos a las revistas, anuarios, memorias, enciclopedias..."; "la fundación o la constitución de organismos institucionales, nacionales o internacionales, que toman como objeto de su preocupación y de una labor colectiva -social- las ciencias sociológicas"; y "la aceptación y consagración de la Sociología misma -disciplina substantivacomo objeto o materia de enseñanza". La pretensión era, en palabras de Posada, la "expansión del conocimiento sociológico" (Posada, 1929a: 99-100). El objetivo era formar un grupo de practicantes con tal de consolidar una "tradición sociológica".

La "adquisición del enfoque sociológico" conllevaba una pugna académica por limitar una disciplina aún desbordante y fronteriza con otras ciencias sociales. Desde una perspectiva histórica se puede observar cómo trataron de desplegar una intensa actividad editorial bajo un esfuerzo colectivo y estimulante: la idea de sacar adelante a la sociología en España. Quisieron destacar entonces como activos mediadores o "pasadores" culturales del conocimiento sociológico contemporáneo. Para la enseñanza de la sociología como disciplina académica en el espacio universitario necesitaban manejar una buena literatura actual. Resultaba muy importante la traducción de obras de autores extranjeros. Para tales tareas se contaba con la experiencia del maestro Posada, introductor en España de la sociología académica norteamericana y quien años antes había traducido al castellano varios trabajos de Ward o los Principios de sociología de Giddings. Ayala y Medina, en cambio, tenían en mente numerosas ideas y lecturas de la incipiente sociología alemana. No extraña, por tanto, que el primer título que apareció en la "Serie H. Obras de Sociología y Filosofía del derecho", de la editorial de la Revista de Derecho Privado fuese el ya citado libro de José Medina, La situación presente de la Filosofía Jurídica, de 1935, donde se acercó a la escuela fenomenológica alemana y se interesó por los

Ampliación de Estudios para estudiar filosofía del derecho y teoría del Estado en Berlín en 1925. Estudió bajo la dirección de Rudolf Stammler y asistió a diferentes cursos sobre filosofía kantiana y post-kantiana, psicología social o filosofía de la historia. Además durante su estancia aprovechó para visitar en Viena a Hans Kelsen, siguiendo de cerca el egregio movimiento de la famosa escuela vienesa de Teoría pura del Derecho. Pero Recasens en su viaje reaccionó también ante la presencia que empezaba a tener la sociología en el ámbito universitario alemán y, en concreto, en Berlín, donde enseñaban Heller, Smend, Sombart o Vierkandt. Memoria de la Junta para Ampliación de Estudios 1926-1928, pp. 69-70. 
estudios sociológicos de Hans Freyer, Ferdinand Tönnies o Max Weber. El segundo título que apareció en 1936 fue El hombre y la sociedad en la época de crisis, de Karl Mannheim, traducido por Francisco Ayala.

Posada transmitió a Ayala y a Medina ese "estar al día" de las corrientes sociológicas contemporáneas, pero además les inculcó un sentido práctico de la ciencia de la sociedad. Para él la sociología debía destacar por su carácter reformador a la hora de resolver los problemas sociales. Apelaba a una "sociología de la acción" para mejorar la vida en sociedad. Según sus palabras, "la Sociología puede ofrecer -será ésta una de sus más interesantes funciones...la justificación esclarecida, científica de la reforma social, o mejor, de la elaboración de esta reforma (continuación reflexiva de la realidad), mediante una preparación detenida, consistente en el estudio en vivo de la realidad social sobre la cual se quiere obrar con la reforma" (Posada, 1929b: 186). En efecto, Posada asumió un papel enérgico y destacado, identificándose con el movimiento reformista de su generación que él, por su parte, compartió con Ayala y con Medina. ${ }^{4}$ Tanto el maestro como los discípulos se interesaron por los elementos objetivos y los soportes institucionales y sociales que facilitan 0 hacen posible la inclinación de una sociedad hacia el pensamiento sociológico, hacia la práctica sociológica o hacia las formas más renovadas de la ingeniería social. Se decantaron por la sociología porque la vieron como la ciencia más capaz de ayudar a las transformaciones sociales que se estaban poniendo en marcha. Manejaron un proyecto de investigación sociológica muy firme que apostó por generar interpretaciones y prácticas que se socializasen en los espacios académico y público.

Necesitaban intervenir y pensar la sociedad que les rodeaba. Tenían una conciencia republicana y social que identificamos con esta inclinación por los estudios sociológicos. ${ }^{5}$ No hubo una lejanía entre su vida y su obra, entre su biografía y entre su interés por participar en los asuntos y reformas sociales. No habrá posibilidad para ellos de distinguir entre el intelectual y el sociólogo. No hay desdoblamiento. Se quiso que la sociología, como la ciencia de la realidad, fuera capaz de intervenir de forma práctica en la sociedad. Interpretaron que el enfoque sociológico era la forma adecuada y necesaria de asumir una conciencia de responsabilidad social con las mejoras democráticas para toda la sociedad española. El pensamiento renovador y reformador es bien visible en este proyecto sociológico de la editorial de la Revista de Derecho Privado. Me permito reproducir el fundamento de esta "tradición sociológica" que trató de constituirse en las condiciones culturales e institucionales de la España republicana:

\footnotetext{
${ }^{4}$ Recordemos que Posada fue discípulo de Francisco Giner de los Ríos y del espíritu de la Institución Libre de Enseñanza. Fue protagonista y testigo del gran proyecto de renovación pedagógica que se acometió en España a principios del siglo XX. Al calor de ese esfuerzo modernizador nacieron organismos como la Junta para Ampliación de Estudios e Investigaciones Científicas, el Centro de Estudios Históricos, la Residencia de Estudiantes o el Instituto Escuela.

${ }^{5}$ Posada militó en el Partido Reformista, fundado en 1912 por Melquíades Álvarez. Ayala y Medina, por su parte, conocieron a importantes republicanos como Luis Jiménez de Asúa o Fernando de los Ríos, que fueron sus profesores mientras estudiaron su doctorado en Madrid. Ayala además había militado con Manuel Azaña en Acción Republicana, a quien había conocido en 1925 en la tertulia literaria del café La Granja El Henar. En el caso del escritor granadino, los acontecimientos políticos y profesionales le alejaron de la escritura entre 1931 y 1939, entre los años de la República y la Guerra Civil, dedicándose más al ensayismo sociológico (García Montero, 2009: 112).
} 
"Con esta nueva serie emprendemos una colección que faltaba aún por completo en la bibliografía española de nuestro tiempo. En ellas se publica un conjunto de obras de carácter sociológico sobre los problemas más vivos y urgentes de la sociedad contemporánea. Los problemas sociológicos han adquirido modernamente un relieve universal, produciendo una floración literaria de extraordinaria riqueza, tanto, que la sociología como ciencia ha llegado o está llegando en estos últimos años a su verdadera madurez y autonomía. Sin embargo, no pretendemos dar únicamente a conocer con esta colección, al público de habla castellana, los mejores resultados de la construcción sistemática de la sociología; más bien se propone esta nueva Serie cultivar lo que hoy día constituye una ramificación de la investigación sociológica: la sociografía y la llamada "descripción de la actualidad". Una y otra, aunque pueden diferenciarse por sus modos de elaboración, coinciden en su interés por el conocimiento de nuestra moderna sociedad en sus más varios fenómenos. Cada vez es más urgente para el hombre moderno, sobre todo en las profesiones que supone una actividad social de cualquier tipo, un conocimiento, el más exacto posible, de la estructura de la sociedad en que vive y actúa. Pero, además, el interés general se ve solicitado singularmente por ciertas manifestaciones sociales que son peculiares de nuestra época o tienen en ella una determinada importancia, y que en este sentido son problemas de nuestra vida. Interesa, por eso, un conocimiento con base científica de las mismas, es decir, sujeto a ciertas garantías de objetividad y exactitud. Con esta colección queremos acudir, ante todo, a satisfacer aquella necesidad. Caracteres sociales de nuestra época: Racionalización y planificación; estratificación social y formas profesionales; familia y vida sexual; efectos sociales del paro; vida escolar; movimientos juveniles; sociología de las diversiones, de la propaganda, de las formas políticas y de la Prensa, etc., todas son cuestiones en las que va implicada de manera fundamental, y a veces sin darnos cuenta de ello, nuestra existencia. En esta colección se publicarán, además, algunas monografías de carácter teórico, dentro de la dirección de la sociología de la cultura, todas ellas de renombre universal hoy día. Con esta nueva Serie damos una prueba más de nuestro constante desvelo en contribuir, en la medida de nuestras fuerzas, al renacimiento de nuestro país, divulgando en obras de lectura atractiva y de solvencia científica mundialmente contrastada un ramo de la cultura cada días más necesario en el proceso de desarrollo y renovación de todos los países civilizados". 6

Visto lo anterior, se puede apreciar algunas líneas básicas sobre las que quiso asentarse esta tradición sociológica de corte reformista: desde la necesidad por incorporar en la lengua castellana el pensamiento sociológico europeo y anglosajón a partir de traducciones y trabajos originales; desde la necesidad de racionalizar y planificar la vida social bajo un espíritu aleccionador y educativo; y desde la sensibilidad por modernizar España a través del aporte práctico de la sociología. Se pensó que la sociología era una forma de contribuir a la transformación social. No había que cambiar España de forma drástica, pero sí ayudar a modificarla. La preocupación que compartieron estos nombres era la modernización del país para que saliera de su atraso y pudiera alcanzar un desarrollo científico, cultural, industrial, político y técnico a la par de los países más avanzados.

\section{El interés por la sociología norteamericana. La voluntad de consolidar una sociología científica.}

\footnotetext{
${ }^{6}$ Solapilla de El hombre y la sociedad en la época de crisis, de Karl Mannheim, Editorial Revista de Derecho Privado, Madrid, 1936.
} 
El empeño reformista de aplicar la sociología como instrumento de mejora y de progreso social iba ligado al deseo de desarrollar científicamente a la disciplina. La sociedad española necesitaba saber más de sí misma, pero lo necesitaba a través del conocimiento científico. La consolidación de una sociología científica implicaba, por un lado, la superación de los esquemas filosóficos del ensayismo social de José Ortega y Gasset, y, por otro lado, la diferenciación con la corriente reformista del catolicismo social de Severino Aznar. La voluntad descansaba en pensar la sociología en otros términos: se pretendió que desempeñara y tuviera un papel relevante en el proceso modernizador ponerla al servicio de la sociedad española-, pero siempre desde un estatus científico. En ese camino dirigido hacia la sociología científica en España sobresalió, una vez más, la figura de Adolfo Posada. Este autor tenía perfectamente claro que el aprovechamiento práctico de esta ciencia no sería posible sin conexión con el trabajo experimental. Ello requería la unión de la sociología académica, más teórica y abstracta, con el interés de una sociología científica, entendida en un sentido técnico y práctico. Precisamente percibió en Estados Unidos el mejor ejemplo de esta combinación teórica y técnica. Decía Posada en concreto:

\begin{abstract}
"es quizá el país donde con más intensidad se trabaja en el estudio de los problemas teóricos de la Sociología, y donde se propende, con más resolución, a considerarla como una disciplina substantiva distinta, y no meramente como el conjunto de las ciencias sociales especiales...la utilidad de su constitución y de su aplicación, en suma, los problemas previos en el desarrollo lógico de una ciencia nueva" (Posada, 1929a: 106).
\end{abstract}

Posada transmitió a sus discípulos ese interés sociológico por los Estados Unidos. Medina, en particular, se contagió de esa fascinación por la sociología anglosajona y por la sociología norteamericana. Esto se aprecia en dos solicitudes que presentó a la Junta para Ampliación de Estudios para postular a una pensión para estudiar sociología en Inglaterra y en Estados Unidos. La primera solicitud, de febrero de 1935, estuvo apoyada por el propio Posada y además por Fernando de los Ríos y Luis Recasens Siches. ${ }^{7}$ Esa postulación fue rechazada. A pesar de eso, esta solicitud es un buen objeto para reflexionar sobre varias claves del campo sociológico español de aquellos años. Oigamos la voz de Medina:

\footnotetext{
"Desde hace algunos años el solicitante venía dedicado a estudios sociológicos, frutos de los cuales hasta el presente ha sido una introducción en la sociología contemporánea que se encuentra en vías de publicación. La formación en esta materia del solicitante ha sido preferentemente alemana, por lo cual se propone en la actualidad completar esa formación, primero, siguiendo un curso teórico en la Universidad de Londres con el Profesor Ginsberg, para adquirir un conocimiento mayor del pensamiento sociológico anglo-americano y segundo, realizando un aprendizaje especialmente en las Universidades de Columbia y de Chicago de los métodos prácticos de investigación sociológica (sociografía y Social Research), con los aparatos empleados para ello, a fin de introducir tales métodos más adelante en nuestro país. Este plan de trabajo expuesto en esquema podría ser explicado oralmente a requerimiento de la Junta. Para asesorar sobre esta materia y mi persona
}

\footnotetext{
${ }^{7}$ Archivo de la Junta para la Ampliación de Estudios e Investigaciones Científicas. Expediente de José Medina Echavarría. Solicitud del 5 de febrero de 1935.
} 
indico a los profesores señores Don Adolfo Posada, Don Fernando de los Ríos y Don Luis Recasens".

Este documento pone muy bien de manifiesto que había un núcleo de nombres que se preocuparon por tapar lagunas y por crear nuevos horizontes dentro del pensamiento sociológico español, y nada mejor que completarlas yendo a los centros extranjeros de conocimiento. La atención por la sociología norteamericana representaba la búsqueda de nuevos límites y fuentes empíricas que dotasen de sentido práctico a un saber teórico aprehendido, fundamentalmente, de las fuentes alemanas y francesas. Se trataba ahora de abarcar el campo del conocimiento sociológico aplicado. El desplazamiento obligado era mirar hacia Estados Unidos. La sociología había tenido un extraordinario desarrollo en aquel país como disciplina universitaria. En 1889 se había creado una cátedra en Columbia y en 1892 un Departamento de Sociología en la Universidad de Chicago. Estos dos centros universitarios fueron los elegidos por Medina para continuar su formación como sociólogo, lo que dice mucho del conocimiento actualizado que había en España sobre la experiencia sociológica en Estados Unidos y su avance en las técnicas de investigación social. Por otro lado, el interés por estudiar junto con Morris Ginsberg era más teórico y analítico, apuntando hacia la construcción, el sentido y el objeto de la sociología. ${ }^{9}$

José Medina Echavarría presentó la segunda solicitud a la Junta para Ampliación de Estudios en febrero de 1936. Su deseo era pasar nuevamente seis meses en Inglaterra y otros seis en Estados Unidos. En Inglaterra esperaba acceder a los fondos bibliográficos de la London School of Economics y poder terminar "un trabajo en preparación sobre la Sociología americana, que proyecto hacerlo, no como mera exposición doctrinal, sino señalando las relaciones y trabazón de ese pensamiento con la historia social y económica de los Estados Unidos en los últimos tiempos". Añadía la posibilidad de "conocer algunos de los profesores de la Escuela, como Ginsberg, Mannheim, Marshall y Malinowski, entre otros". ${ }^{10}$ Con esta estancia pretendía hallar las fuentes teóricas de la sociología científica. En Estados Unidos, en cambio, aspiraba a conocer los laboratorios de investigación sociológica de las Universidades de Columbia y de Chicago. A la teoría había que sumarle su aplicación:

"hay algo que por mí o por otros creo que debe ser conocido y, en parte, asimilado. Me refiero al conjunto de instrumentos e instituciones dedicados en Norteamérica a la llamada Social Research Work: los procedimientos de las surveys, el instrumental estadístico y cartográfico, las formas de los Case Work, tipos de cuestionarios e interview, etc. No tengo que indicar a la Junta la significación y el valor de algunos Social Laboratorys en los Departamentos sociológicos de las Universidades norteamericanas, ni la importancia de determinadas fundaciones e instituciones privadas que sostienen y cooperan a las tareas de investigación social". ${ }^{11}$

\footnotetext{
${ }^{8}$ Archivo de la Junta para la Ampliación de Estudios e Investigaciones Científicas. Expediente de José Medina Echavarría. Solicitud del 5 de febrero de 1935.

${ }^{9}$ Medina traduciría en 1942 para la editorial argentina Losada el Manual de Sociología de este sociólogo.

${ }^{10}$ Archivo de la Junta para la Ampliación de Estudios e Investigaciones Científicas. Expediente de José Medina Echavarría. Solicitud del 5 de febrero de 1936, fojas 19-20.

${ }^{11}$ Archivo de la Junta para la Ampliación de Estudios e Investigaciones Científicas. Expediente de José Medina Echavarría. Solicitud del 5 de febrero de 1936, foja 19.
} 
Medina fue intérprete, no obstante, de ese anhelo compartido por construir científicamente la sociología en lengua castellana. Estas solicitudes simbolizan, en todo caso y como hemos destacado en páginas anteriores, la existencia de una voluntad colectiva a favor de los estudios sociológicos. Nombres como los de Ayala, el mismo Medina, Posada y el también citado Recasens Siches intuyeron la dirección que luego tomaría la sociología occidental tras la Segunda Guerra Mundial: junto con el marco teórico, la sociología debía apoyarse necesariamente en los métodos y en las técnicas de investigación social. Ellos supieron que no se podían quedar en el plano reflexivo y, por tal motivo, insistieron en alcanzar en España un soporte institucional para el desarrollo operativo y práctico de la sociología.

La Junta para Ampliación de Estudios finalmente le concedió a Medina el 8 de julio de 1936 la pensión que había solicitado para estudiar sociología en Inglaterra y en Estados Unidos. ${ }^{12}$ Nunca la llegó a disfrutar. Pocos días después, el 18 de julio, comenzaba una Guerra Civil que puso fin a muchas expectativas e ilusiones depositadas en la modernización cultural y social de la República española. Por lo que respecta a la sociología, se interrumpió la aventura por institucionalizar una tradición científica, democrática y reformista. No se cumplieron las esperanzas colectivas, según las palabras del propio Medina, de crear "en nuestro país algún instituto de investigaciones sociológicas". ${ }^{13}$ También el proyecto que Ayala, Medina y Posada tenían en la editorial de la Revista de Derecho Privado se truncó. Se esperaban la traducción y la publicación de libros de Paul Lazarsfeld, Ferdinand Tönnies o Max Weber, además de la Introducción a la sociología contemporánea del propio Medina Echavarría, que eran sus apuntes y notas del curso que dictó en la cátedra de Posada. Véase si no el testimonio de Medina:

\begin{abstract}
"En el año 1934 Don Adolfo Posada -recordaba- patrocinó un cursillo, dado por mí en la Facultad de Derecho de esta Universidad, sobre los problemas fundamentales de la actual Sociología. Constituyó esto mi primera contribución a la propaganda e iniciación de los estudios sociológicos hoy renacientes. Redactado casi por completo aquel cursillo en forma de una introducción a la Sociología Contemporánea, las exigencias de unas oposiciones posteriores me obligaron a abandonar aquel trabajo que ahora, ligeramente modificado va a publicarse por la Editorial de Derecho Privado. En esa Editorial dirijo en este momento una colección de libros sociológicos de la que en este año aparecerán obras de los Mannheim, Tonnies, Weber, Michels, Ruggiero, Lazarsfeld, Jehodn y Burns". ${ }^{14}$
\end{abstract}

Es más que probable que estos autores, sin la quiebra cultural producida por la guerra, hubieran desarrollado a niveles más que aceptables el campo sociológico español y hubieran adelantado en decenios la recepción de corrientes sociológicas como la histórica-cultural o la empirista. Si se hubiera acometido la traducción de Max Weber en una España en condiciones democráticas y políticas normales se hubiera anticipado la recepción de la sociología comprensiva y se hubiera puesto a la sociología española en una punta de conocimiento que, por ejemplo, no había en Estados Unidos, donde

\footnotetext{
${ }^{12}$ Archivo de la Junta para la Ampliación de Estudios e Investigaciones Científicas. Expediente de José Medina Echavarría.

${ }^{13}$ Archivo de la Junta para la Ampliación de Estudios e Investigaciones Científicas. Expediente de José Medina Echavarría. Solicitud del 5 de febrero de 1936, foja 18.

${ }^{14}$ Archivo de la Junta para la Ampliación de Estudios e Investigaciones Científicas. Expediente de José Medina Echavarría. Solicitud del 5 de febrero de 1936, foja 18.
} 
Weber era un autor aún casi por descubrir (Morcillo, 2008). Son cosas imposibles de saber, porque la historia fue otra. Lo que sí sabemos es que Ayala y Medina trataron de introducir y renovar esta tradición sociológica reformista, deudora del pensamiento alemán y del clima cultural de la Segunda República española, en Argentina y en México, sus países de acogida en el exilio latinoamericano. Con el tiempo desarrollarían y completarían esta tarea editorial y pedagógica desde distintos frentes y geografías, pero consolidando y manteniendo una importante red de colaboración entre científicos sociales y sociólogos del exilio intelectual. ${ }^{15}$

\section{Para concluir: la conveniencia actual de nuestros clásicos y de sus legados intelectuales.}

Los sucesos históricos caracterizan en muchas ocasiones, irremediablemente y de forma tan tremenda, las suertes individuales y las obras colectivas. En este trabajo hemos pretendido narrar la voluntad de una serie de autores que trataron de formalizar a la sociología dentro del campo científico y proveerla de unos límites académicos, teóricos, operativos e institucionales que hasta entonces no tenía. Cuando justamente la sociología en España comenzaba a dar sus primeros pasos firmes hacia su autonomía, la Guerra Civil puso fin a todos estos esfuerzos. El núcleo más joven de este proyecto modernizador se tuvo que ir al exilio, justo en el momento en el que habían conseguido superar el estado de una sociología "preparadigmática" (Morente, 2000: 279). Los grupos de investigación sociológica que se iban a montar se decapitaron. Se perdieron estudios, monografías, libros, traducciones, y se interrumpieron transferencias culturales provenientes de los centros sociológicos extranjeros. El franquismo debilitó y cortó el desarrollo natural de la sociología española como el avance de cualquier disciplina (De Miguel, 1979: 5 y 16). Se retrasó el camino iniciado hacia la sociología científica, motivado también por el monopolio del catolicismo social de Severino Aznar durante el período nacional-católico del régimen franquista.

Pero la alusión a estos cortes no nos imposibilita trazar algunas continuidades sobre la historia de la disciplina. No debemos marcar una dicotomía demasiado rígida entre exilio e interior. Por ejemplo, si Adolfo Posada jugó un papel determinante al ser la llave entre la vieja sociología del siglo XIX y la nueva sociología del XX, al anticipar direcciones y preocupaciones, a Enrique Gómez Arboleya le correspondió un papel similar como engarce entre la generación de Posada y la "Generación de 1903-1918" o la "Generación de sociólogos de la Guerra Civil". Este autor se hizo cargo de la primera cátedra de Sociología en

\footnotetext{
${ }^{15}$ Una muestra de esta relación fue la colaboración entre Ayala y Medina, quienes establecieron una red de ideas entre Buenos Aires y México desde la editorial Losada y desde el Fondo de Cultura Económica, respectivamente. Aparecen como autores y traductores de libros sociológicos. Además también participan otros nombres que habían colaborado en la editorial de la Revista de Derecho Privado, como Vicente Herrero, Eugenio Ímaz o Luis Recasens Siches. Una de las mayores aportaciones de estos autores a la sociología latinoamericana y a la sociología en lengua castellana fue la traducción de Economía y sociedad, de Max Weber. José Medina, como intermediario en México de las ideas sociológicas de Weber, se encargó de encabezar el equipo que tradujo esta titánica obra para el Fondo de Cultura Económica. El equipo de traductores estuvo compuesto por Juan Roura Parella, Eduardo García Máynez, Eugenio Ímaz y José Ferrater Mora. La traducción se prolongó durante cuatro años, desde 1940 hasta 1944, en unas condiciones nada cómodas.
} 
la posguerra y lo hizo desde la misma tradición germanizante en que sus predecesores exiliados - Ayala, Medina, Recasens- lo habían hecho. ${ }^{16} \mathrm{La}$ atención hacia las voces del exilio sociológico fue difícil y dolorosa por parte de esta voz del interior (Gómez Arboleya, 1958). Uno de sus mayores esfuerzos fue mantener el interés por la sociología empírica anglosajona y por las nuevas técnicas de investigación social (Marsal, 1977: 113-114). Con Gómez Arboleya continuó esa línea de pensamiento reformista, moderado, liberal y cosmopolita que había en la tradición de la disciplina y que unió tanto a los sociólogos del exilio como a los sociólogos del interior y a los pensadores que han tratado temas sociológicos. Su prematuro fallecimiento en 1959 impidió, sin embargo, dar una mayor continuidad a una tradición sociológica compartida fuera y dentro de España. Después la sociología del interior seguiría otros derroteros bien diferentes.

Toda esta reflexión sobre la experiencia de las prácticas sociológicas y la mirada desde un pasado-presente es la que nos ha permitido la comprensión de un patrimonio de conocimiento acumulado que es importante conocer y hacer contemporáneo. Esta tarea implica una reflexión sobre las cadenas de aprendizaje en nuestras comunidades intelectuales. En la elaboración de esta investigación ha subyacido, efectivamente, el deseo de dar a conocer una historia digna de ser tomada en cuenta por la sociología española. Solo la definición y el conocimiento de los legados intelectuales como la identificación de las aportaciones de nuestros antecesores puede reconducir el debate teórico contemporáneo de la sociología en lengua castellana y de la historia de la sociología en España. La potenciación del discurso de nuestros clásicos permite, sin duda, el establecimiento de una ciencia plenamente autónoma y adecuadamente institucionalizada.

\section{Referencias bibliográficas}

Ayala, Francisco (2006): Recuerdos y olvidos, Alianza Editorial, Madrid.

Bottomore, Tom; Nisbet, Robert (1979): "Introduction". En Tom Bottomore y Robert. Nisbet (Eds.), A History of Sociological Analysis, Heinemann, Londres, pp. VII-XVI.

De Miguel, Jesús M.; Moyer G. Melissa (1979): "Sociology in Spain", Current Sociology, 27, pp. 5-138.

Del Campo, Salustiano (Dir.) (2001): Historia de la sociología española, Ariel, Barcelona.

García Montero, Luis (2009): Francisco Ayala. El escritor en su siglo, Los libros de la estrella, Diputación de Granada, Granada.

Giner, Salvador (2007): "Entrevista a Salvador Giner", en Mariano Pérez Yruela, Teresa González de la Fe, Teresa Montagut (Comps.), Escritos sociológicos. Libro homenaje a Salvador Giner, Centro de Investigaciones Sociológicas, Madrid, pp. XIII-XLIX.

Giner, Salvador; Moreno, Luis (Eds.) (1990): Sociología en España, Consejo Superior de Investigaciones Científicas, Madrid.

\footnotetext{
${ }^{16}$ La influencia alemana fundamental en Gómez Arboleya es la de Hermann Heller, a quién dedicó su tesis doctoral de 1935, y quien le hizo orientarse hacia un socialismo de corte humanista.
} 
Gómez Arboleya, Enrique (1958): "Sociología en España", Revista de Estudios Políticos, 98, pp. 47-83.

Gutiérrez, Rodolfo (2001): "Adolfo Posada: reformismo y eclecticismo". En Salustiano del Campo (Dir.), Historia de la sociología española, Ariel, Barcelona, pp.83-99.

Juliá, Santos (1990): Manuel Azaña. Una biografía política, Alianza Editorial, Madrid.

Lepenies, Wolf (1994): Las tres culturas. La sociología entre la literatura y la ciencia, Fondo de Cultura Económica, México.

López-Ocón, Leoncio (2003): Breve historia de la ciencia española, Alianza Editorial, Madrid.

--2010) "La dimensión educativa del Centro de Estudios Históricos en su etapa fundacional", en José Manuel Sánchez Ron y José García Velasco (Eds.), 100 años de la JAE. La Junta para Ampliación de Estudios e Investigaciones Científicas en su Centenario, Fundación Francisco Giner de los Ríos, Publicaciones de la Residencia de Estudiantes, Madrid, pp. 40-71.

Mannheim, Karl (1936): El hombre y la sociedad en la época de crisis, Editorial Revista de Derecho Privado, Madrid.

Marichal, Juan (1995): El secreto de España. Ensayos de historia intelectual y política, Taurus, Madrid.

Marsal, nJuan Francisco (1977): Teoría y crítica sociológicas, Biblioteca Universitaria Guadiana, Madrid.

Martín, Sebastián (2011): "Estudio preliminar", en Sebastián Martín (Ed.), El derecho político de la Segunda República. Francisco Ayala, Eduardo L. Llorens, Nicolás Pérez Serrano, Universidad Carlos III, Madrid, pp. XICLXXXIX.

Medina Echavarría, José (1934): Introducción a la sociología contemporánea, Archivo General de la Administración, Alcalá de Henares, caja 32/13534.

- (1935) La situación presente de la filosofía jurídica: esquema de una interpretación, Editorial Revista de Derecho Privado, Madrid.

Morcillo, Álvaro (2008): "Historia de un fracaso: intermediarios, organizaciones y la institucionalización de Weber en México (1937-1957)", Sociológica, 67, pp. 149-192.

Morente, Felipe (2000): "Sociología en España. Una aproximación sintética", Revista de Estudios Políticos, 108, pp. 271-292.

Ribes, Alberto J. (2007): Paisajes del siglo XX. Sociología y literatura en Francisco Ayala, Biblioteca Nueva, Madrid.

------- (2011) "Visiones sobre la sociología española: hacia las narrativas abiertas y sacerdotales", Nómadas. Revista Crítica de Ciencias Sociales y Jurídicas, 32, pp. 545-558.

Rodríguez Ibáñez, José Enrique (2004): "Epílogo", Política y Sociedad, Vol. 41, 2, pp.199-201.

Sarabia, Bernabé (2001): "Precursores de la sociología española. Siglo XIX", en Salustiano del Campo (Dir.), Historia de la sociología española, Ariel, Barcelona, pp. 17-40.

Posada, Adolfo (1892): "Los fundamentos psicológicos de la Educación según el Sr. González Serrano", Boletín de la Institución Libre de Enseñanza, no 358.

- (1929a) Principios de sociología, Tomo I, Daniel Jorro editor, Madrid.

(1929b) Principios de sociología, Tomo II, Daniel Jorro editor, Madrid. 